\title{
THE SUBTERRANEAN ENVIRONMENT
}

\author{
A. I. Camacho and A. G.-Valdecasas \\ Museo Nacional de Ciencias Naturales. José Gutiérrez Abascal 2. 28006- Madrid. Spain.
}

Keywords: Groundwater, Interstitial fauna, Natural History, Phylogeny, Adaptation and Evolution.

\begin{abstract}
This paper is a short essays on the fauna that inhabits the subterranean environment and its bearing to some critical and present day problem in Evolutionary Biology, with a review of the work done on Spanish subterranean waters.
\end{abstract}

\section{INTRODUCTION}

\section{Overview}

The recent history of science should be a focus of attention for those areas of scientific research where a new discipline arises. Much sterile discussion and effort could be avoided if we learnt how similar problems were posed and solved in nearby fields. Or, at least, the kind of involvement that should be avoided.

Habitat classification in what we here call the subterranean environment is a good example of this. Caves have been known and used since human origins. The interstitial layers, Epigean and Hypogean that are beneath and surround streams and lakes were known to have a fauna during the first half of this century. Both share the absence of light as the main joint characteristic. Deep sea also lacks light, but water composition makes a big difference. All of them could be properly called subterranean environments- under something, be it terra, freshwater or marine water-. We deal here only with those subterranean that could properly be called freshwater.

In order to avoid discussion and to clarify the subject, the first question to answer is what we understand by habitat or "restricted environment". There are two ways of dealing with this problem. One is to make distinctions and classifications of the physical space based on the discontinuities humans can discriminate visually or by any other way. After the environment is subdivided into homogeneous parts it is assumed that, all else being constant, similar parts will have similar inhabitants. The alternative approach is to look for similar inhabitants first and assume that the physical space where they live is equivalent in some way. Of course, many approaches are possible between these two limits and Nature is generally indifferent to our efforts to clarify issues.

In the area of Limnology, the trend on Regional Limnology (NAUMANN, 1932) of the second quarter of this century, the efforts to classify lakes on a eutrophic-oligotrophic dimension or. more recently the discussion on continuum versus discrete in lotic environments (VANNOTE et al., 1980; BARNES \& MANN, 1980), are good examples of the limited success of classificatory squemes in Nature.

Having said that, we would like to note that the subject of this chapter is the fauna that inhabits the interstitial environment of streams, either superficial or inside caves, and all other aquatic organisms inside caves. All of them share the absence of light, and although we realize it is more or less arbitrary to use this as a delimitatory criteria, we found other criteria even more arbitrary. A more precise concept of this subterranean environment follows.

\section{Cave and Interstitial fauna.}

The subterranean aquatic environment is built up of two sets which have been long since clearly differentiated: subterranean water sensu strictu and interstitial water. Subterranean water in its broadest sense is found in caves and pits, from fissures and cracks inaccessible to humans to big cavities where subterranean streams flow, to completely inundated galleries (siphons). The interstitial water flows through the sand grains and gravel deposits of littoral beaches, alluvial layers at the edge of rivers and lakes and the upper part of the sediments below the river bed (hypo- 
rreic, ORGHIDAM, 1953) as well as the hypotelminorreic layer (MESTROV, 1964).

In caves, the invertebrate fauna of the Iberian Peninsula lives in small ponds, gours, lakes, at the bottom of defiles, subterranean river shores and in any other source of water. Some of these animals, such as Crustacea Syncarida live strictly in this type of water; others have hypogean and epigean species like the copepods, and some, like the isopod Stenasellus live well in either environment. This has made it very difficult to delimit the subterranean fauna and a great variety of criteria ecological, etological or topographical has been used to produce classification. The most general classification and perhaps the most accepted had its origin in Schiner-Racovitza which considers three categories of subterranean animals: troglobious, a strictly cave animals whose life cycle takes place completely in the cave; troglofilous, a frequent inhabitant of the caves, adapted ecologically but not morphologically, and trogloxenus, casual inhabitants, whose long permanence in the caves could cause them to die. More recently CHAPMAN (1986) takes the view that the only valid criteria for a classification is that based on a single common characteristic and with a deep biological significance: the absence of light. The scarce knowledge we have about the majority of the species that live in subterranean water projects no light on the degree of adaptation of this fauna to its environment. The interstitial or phreatic fauna that could be found in the other dominium of the subterranean waters, and that could only be reached through artificial wells, the Karaman-Chappuis sampling method (CHAPPUIS, 1942; MOTAS, 1962) or the Bou-Rouch method (BOU, 1974), is composed of permanent frequent, or occasional inhabitants as is the case of cave animals.

The most complex classification of this environment could be found in HUSMANN (1966-1971), who creates categories for the fauna as a function of the stream stretch, in terms of the classical river classification, the size of the sediment, adaptation and permanence in the environment (habitual, frequent, or occasional). This kind of classification is usually avoided today, as it is very difficult to assign the fauna univocally to any of its categories. There are animals that spend only a part of their life cycle in this environment as do some insect larvae. At this stage, they should be properly considered subterranean inhabitants.

\section{Brief historical review.}

The studies on biospeleology have evolved in Spain in a similar fashion to those in other countries but at a lower intensity and with a certain delay at the beginning.
The first records of Spanish biospeleology, around 1861, come from foreign researchers, and the main emphasis is on taxonomy of the terrestrial cavernicolous fauna. The first aquatic animal, discovered by Racovitza in 1905 was the isopod Typhlocirolana moraguesi in the Cuevas del Drach, Mallorca. The first half of this century witnessed an increase in knowledge in very different groups by researchers like Chappuis, Viets, Coiffait or Delamare Deboutteville. In Portugal, on the other hand, it was the local researchers who made the earlier contributions to their fauna: names like Braga, Frade or Mateus are the most prominent of this period. By the fifties Margalef begins to publish his contributions on cavernicolous crustacea. By 1960 there is an increased interest in sporting speleology, and inside the new clubs, especially in the Basque and Catalan provinces, a growing group of naturalists creates the "criticum minimun number" that makes biospeleology an established activity in Spain. Foreign and local researchers have recently contributed to the knowledge of our fauna, and a visual summary of what is presently known in relation to the world subterranean fauna is presented in figure 1 . It could be said that subterranean fauna is still very poorly known in this area, although, as the figure 1 shows, the proportion of species in relation to what is known elsewhere is rather high, especially in groups like Isopoda, Copepoda and Amphipoda.

\section{A REVIEW OF THE NATURAL HISTORY OF THE SUBTERRANEAN AQUATIC ENVIRONMENT.}

On the adaptative value of form and the effects of the absence of light

Life in caves and the interstices have mistified the approaches of scientists to the understanding of adaptation. The afore mentioned properties such as lack of light, constant environmental variables like humidity or temperature and the scarcity of food, have led cave researchers to directly correlate some organism features with any of these properties. Interstitial space, for example, has been thought adequate for "verm" type organisms, while the lack of light is thought responsible for the absence of eyes and pigmentation (table 1).

As in any other area of field biology, close correlation between organism features and environment has led to two serious problems. First, the need to understand or to prove that the correlation is a real result of adaptation. Second, and 
Table 1. Features of interstitial and cave animals.

\begin{tabular}{lll}
\hline INTERSTITIAL & COMMON & CAVES \\
\hline Dwarfism & Anoftalmia & $\begin{array}{l}\text { Dwarfism/Gigantism } \\
\text { Appendages enlargement }\end{array}$ \\
Positive Ticmotactism & Dispigmentation & Metabolic economy \\
& $\begin{array}{l}\text { Better touch and chemical } \\
\text { senses }\end{array}$ & \\
$\begin{array}{l}\text { Enlargement and compression } \\
\text { of the body }\end{array}$ & $\begin{array}{l}\text { Laedomorphism } \\
\text { Longer life cycle }\end{array}$ \\
Adhesive organs & $\begin{array}{l}\text { Low fecundity } \\
\text { Lesser number of eggs } \\
\text { Increase in egg size }\end{array}$ & \\
\hline \hline
\end{tabular}

mainly of historical interest- although there are still scientists that maintain unorthodox points of view- the mechanism which explain that adaptation. For some reason, caves have been the subject of very involved debates between Darwiniar and Lamarckian theorists (e.g. the early century debate in Nort America), and even some contemporary researchers like ANDEL (1964). DELAMARE DEBOUTTEVILLE (1973) were dissatisfied with the Darwinian explanation.

Although the understanding of the mechanisms of adaptation is a challenge, no less important is the previous step: establishing that some organ or set of morphology is the result of adaptation. Until now, descriptions of the features of organisms were offered as the only scientific result. The subject of the third part of this paper, is precisely how to prove that some feature is the result of a process of adaptation to certain environmental characteristics. But before dealing with this aspect, let us indicate how impressed other researchers have been by what seems to be very good "fitness" to the environment.

Our first example is the water mite Frontipodopsis reticulatifrons SZALAY, 1954. This species is usually found in the interstices of streams, as sampled by the Karaman-Chappuis method, fig. 2a. It is a laterally compressed animal, with very strong fourth legs. There are only three basic body forms in water mites: globular, that are common in the still waters of ponds, lakes and streams, dorso-ventral compressed forms, frequent in streams and rivers, and laterally compressed forms. Only two kinds of water mites, Fronti- poda, that live in still waters, and Frontipodopsis, show this last body form. The two environments are so different in terms of the demands on locomotion, that it is difficult to accept that both cases are adaptations to the environment. We should not forget the critical advice of GOULD \& LEWONTIN (1979) to avoid the analysis of every aspect of an organism as an adaptation. But we are still confronted with the problem of recognizing those that really are.

The second example is a cave Syncarid of the genus Iberobathynella (fig.2b). The most prominent features of this organism are its slender body form, the lack of eyes and

\section{№ of species}

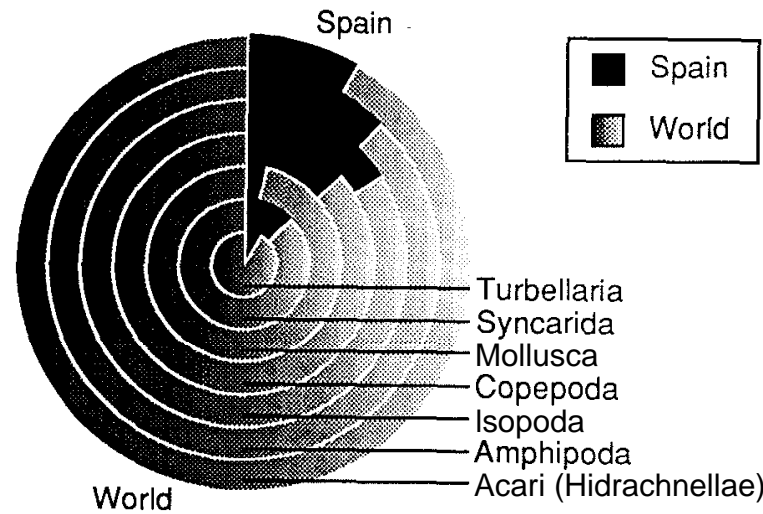

Figure 1. Relationship berween number of subterranean species in Spain versus the world. 
the total dispigmentation of the body. As almost all syncarids are cave inhabitants, we are not confronted here with contradictory evidence in the same group. One is, then, tempted to assign these characteristics to the life in caves. Nevertheles, all these characteristics are found in other organisms outside the cave environment (VANDEL, 1964), so one is still uncertain of the origin of these characteristics in Iberobathynella.

Finally, our third example is the isopod Cantabroniscus primitivus (fig. 2c) an amphibian inhabitant of caves that lacks eyes and is dispigmented. In this case, the temptation to assign these characteristics to the life in caves is higher than with Iberobathynella, as the close relatives of Cantabroniscus, the wood louses, are heavily pigmented, have eyes and do not play in water.

What is needed in all these cases is an objective way of establishing if a character is present in an organism as a result of its being inherited from an ancestor os if it has arisen as a new character in the organism under study. Ways to as certain this follow.

\section{UNDERSTANDING THE EVOLUTIONARY HISTORY.}

\section{A methodological preamble.}

The understanding of the organic diversity (morphological, developmental and ecological patterns) shown by the aquatic subterranean fauna can be treated with the tools of Systematics. Characters, classifications and cladograms are the basic materials in the search for the evolutive process that has led to those patterns.

The first methodological step is to split the evolutive part from the phylogenetic component (heredity). If a character is not inherited but acquired through the evolutive history of the taxon we should then look for a casual explanation, be it adaptative (natural selection working as an answer to an environmental situation) or not (random changes, genetic drift, etc.).

Only a few groups have detailed developed phylogenies, but classifications are more common, even in subterranean taxa. We can move from a phylogenie to a classification using the convexity criterium (ESTABROOK, 1978; DUNCAN, 1980; MEACHAM, 1980; MEACHAM \& DUNCAN, 1988). With this criteria the results from cladistics studies and previus classifications could be compared, and estimations of the evolutive history revised.
Evolutive explanations can be derived from functional explanations in morphology ("completeness" sensu BOCK, 1988) using the tools of Systematics. Morphological studies try to uncover functional explanations produced by experimental methods and evolutive explanations by comparative methods, all embodied inside a phylogenetic framework. The comparative method (RIDLEY, 1983; HUEY, 1978; PAGEL \& HARVEY, 1988, 1989, 1990; PAGEL, 1988) uses the fact that similar evolutive results come, very frequently, as a response to selective forces and not only randomly. Correlate changes support the evidence of a general adaptative relation. With this method one can identify how phenotipic components tend to covariate among themselves and with the type of life. Such patterns have been used to suggest and test adaptative explanations of organic diversity. Characters that are evolutively independent should be examined together to detect adaptative convergence.

The main obstacle of the method is how to distinguish the similarities due to a common ancestor and the similarities due to parallel and convergent changes.

In order to study the evolution of ecological characters using the comparative method, the most adequate taxonomic level is the species (TELENIUS et al., 1989) and their phylogenetic relationships. The phylogenetic trees should be derived independently from the ecological data. Only those characters that phylogenies show to be new (autopomorphies) could be candidates to discover explanations that affect actual environmental conditions and look for causal relationships between the characters and the environment (TELENIUS ef $a l ., 1989$ ). The ground for this hypothesis is the common connection between environment and character.

Phylogenetic Systematics and Ecology answer qualitatively different questions: relations and history versus process and adaptation.

The renewed interest in comparative analysis in ecology is due to the advent of new methods in Systematics and any field of Biology with a comparative component is favoured by the introduction of the phylogenetic view as one of its tools.

\section{Using copepods as model organisms.}

In 1968 ROUCH published a detailed study on the biology of subterranean copepods. His data has been used by other authors (e.g. CULVER, 1982), and is specially relevant to the matters we have been discussing up to now. Table 2 is a resumé of the data of Rouch. 

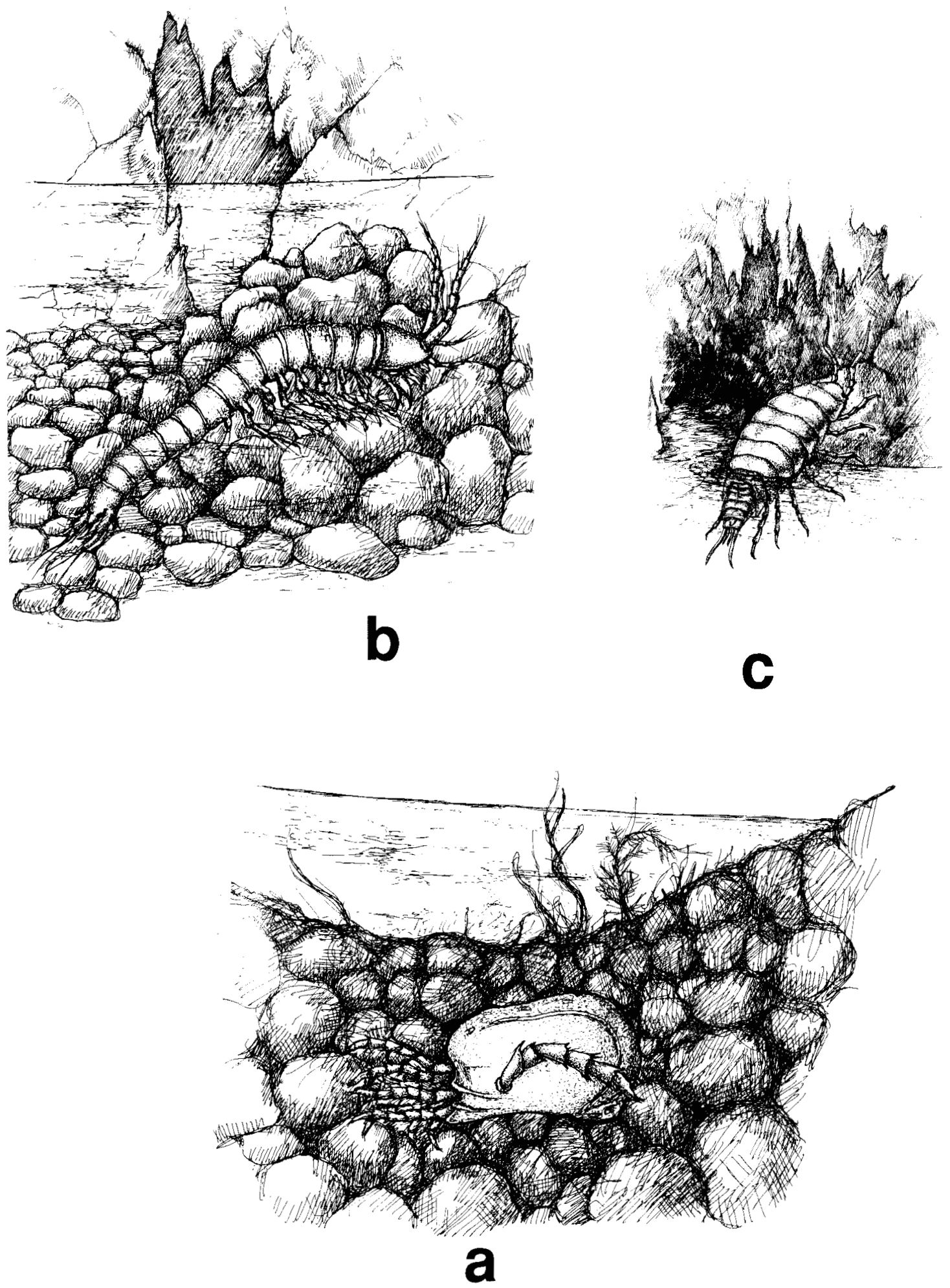

Figure 2. Some examples of subterranean inhabitants. a) Fronipodopsis reticulatifirons. b) Iberobathynella sp. c) Cantabroniscus primitivus. 
Establishing the correlation between organism/ environment characteristics.

The number of eggs carried by the copepod female is very variable, ranging, in the case of those species studied by ROUCH (op. cit.) between 1 and 45. A correlation of this variable with an environmental variable could pave the way for a later, deeper phylo-ecological analysis. But before this, we have to exclude other single causes of female fertility, such the as, female size. Size has been know to influence the fertility of many organisms. Table 2 gives a resumé of the species studied by Rouch, their habitat, number of specimens studied per species, mean size of female per species, mean and range of number of eggs and the coefficient of determination for single species, species by habitat, total of species and food-habitat (see below). The relationship of female size with number of eggs (fig.3), is a weak one when analysed by species or by the total number of species. This result makes us suspect that relatively high $\mathrm{R}^{2}$ of low altitude epigean species could be due to another factor. It is known that caves and high altitude epigean environments are poor food sources, while low altitude epigean environments are rich food environments. We have divided the thirteen species into two groups, low food group and high food group. $\mathrm{R}^{2}$ for this relationships is 66.1 , pointing to a clear contribution of food to fertility. It should be pointed out that the group with high food environment is the same that gives the high $\mathrm{R}^{2}$ between female size and fertility. A more detailed analysis is in preparation.

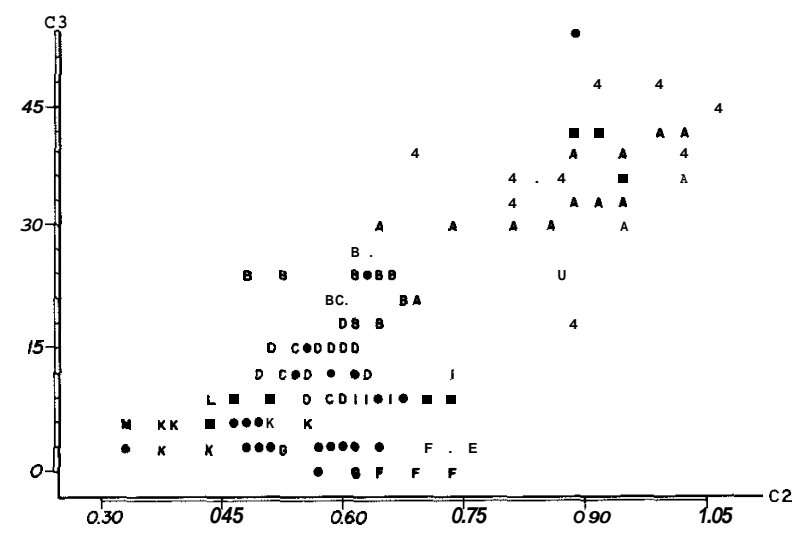

Figure 3. Relation of number of egg versus female size in copepods. Correspondence between letters and species can be found in Table 2 . Circles (.) denote multiple specimens.

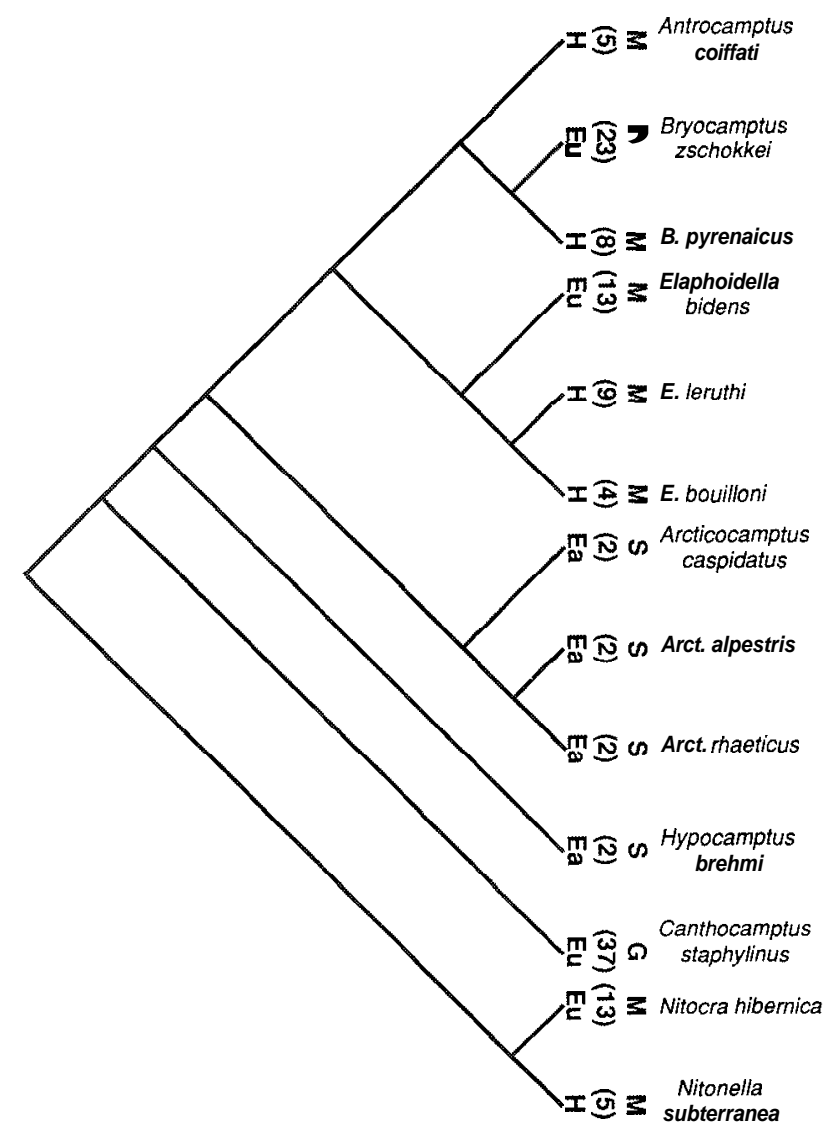

Figure 4. Preliminary copepod cladogram based in Lang (1948) classification. S: small, M: medium, G: high number of eggs. H: cave species; Eu: low altitude epigean species; Ea: high altitude streams \& pond species. Number between brackets are mean egg number.

\section{Determining the phylogenetic origin of organism} features.

We could test to see if the number of eggs carried by the female copepod were a phylogenetic trend, that is a character inherited from an ancestor superimposing the values of this variable to a cladogram of the group. Figure 4 is a preliminary cladogram based on the classification of LANG (1948). As the relationship between copepod taxa is a relatively undeveloped subject, this analysis should be taken more from a heuristic point of view than a causal-effect analysis. To this cladogram we have added the habitat where the species lives and the fertility, divided into three categories: small number of eggs ( $\mathrm{S}, 1-2)$, medium $(\mathrm{M}, 3-17)$ and high $(\mathrm{G},+18)$. This subdivision (as any other alternative) is problematic, but until we have more information on the fertility variable, it is as good as any other. 
Table 2. Data of copepods used in this study (from Rouch, 1968). N: number of specimens. Xs: female mean size. Xe: female mean egg number. R2: coeficient of determination for the egg number/ size relationship.

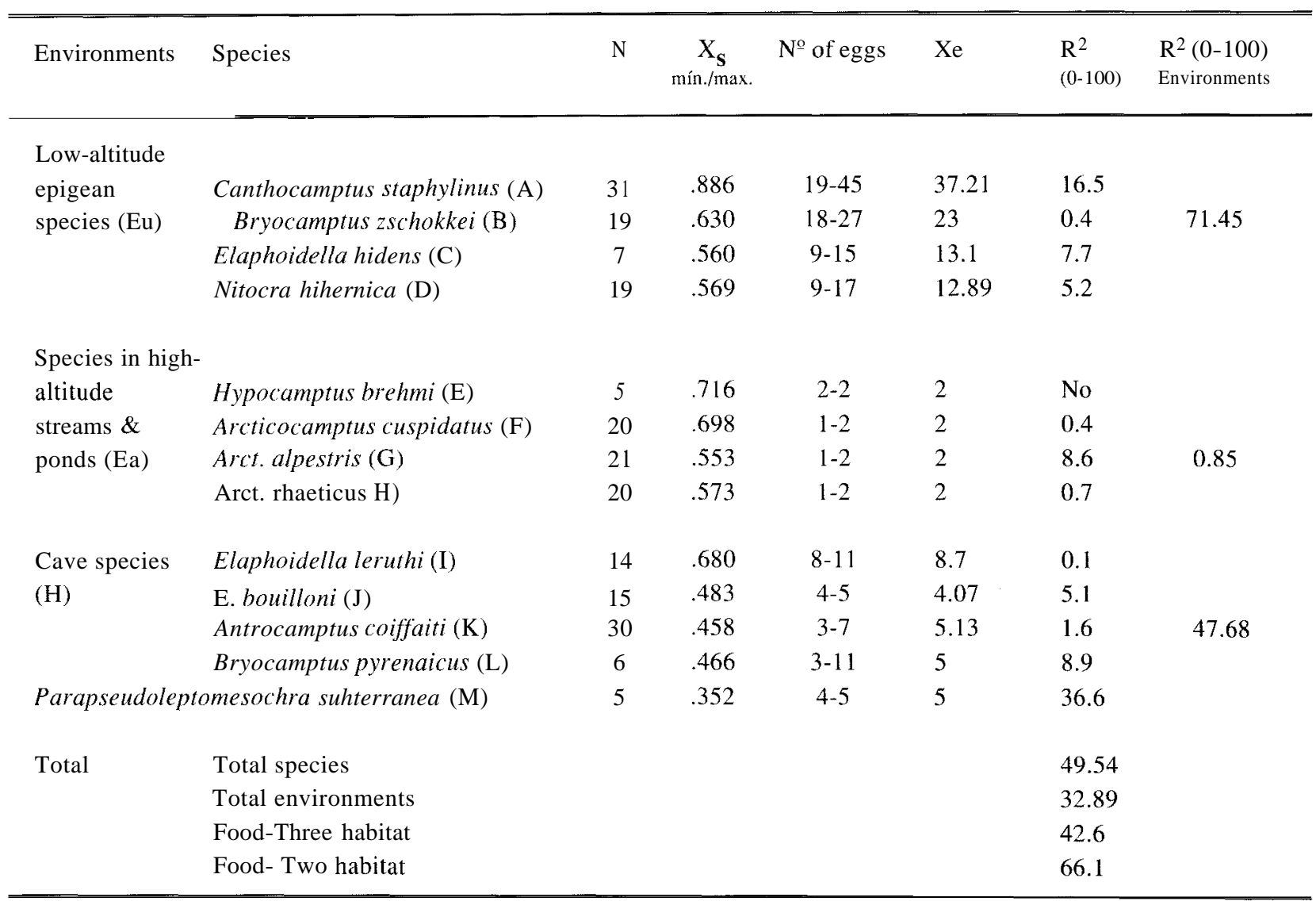

In this situation, the most parsimonious hypothesis is that the ancestor of this group of species carried a medium $(\mathrm{M})$ number of eggs, some species then evolved to high $(\mathrm{G})$ and the others to low (S) number of eggs. The causal force of this evolution has not been exclusively due to food abundance. There is overlapping in egg number between low land epigean species and hypogean species (3-11, 9-15). To add to the confusion, some species classified as low land epigean species like B. zschokkei and Nitroca hihernica (1827 and 9-17 eggs respectively) have been found as well in the hypogean environment.

This kind of analysis, despite the methodological difficulties, is a powerful tool to establish with precision, which properties of the organisms are really true adaptations and helps to understand the true forces of evolution. We hope we have shown the possibilities of this kind of analysis. Future studies of subterranean adaptation should take advantage of it.

\section{ACKNOWLEDGEMENTS}

We greatly appreciate the help of R. Rouch, N. Coineau, C. Puch, N. Vaticón, E. Bello, J.M. Becerra. Jill Riordan checked the english.

This research was suported by funds provided by DGICYT funds № PB87/0318 and PB87/0397.

\section{REFERENCES}

BARNES, R.S.K. \& K.H. MANN, (Eds.) 1980. Fundamental of Aquatic Ecosystem.. Blackwell Scientific Publications, Oxford. 229 pp.

BOCK, W.J., 1988. The nature of explanations in morphologie. Amer. Zool. 28: 205-215.

BOU, CL.. 1974. Les méthodes de récolte dans les eaux souterraines interstitielles. Ann. Spéléol. 29 (4): 611-619 
CHAPMAN, P., 1986. Non-relictud cavernicolous invertebrates in tropical Asian and Australasian Caves. 9e. Cong. Int.Speleol., Barcelona. 2: 161-163.

CHAPPUIS, P.A., 1942. Eine neue methode zur Untersuchung der Grundwasser fauna. Act. Scientiarum math. nat. 6, Kolozsvar: 3-7.

CULVER, D.C., 1982. Cave life. Evolution and Ecology. Harvard University Press, Cambridge. 189 pp.

DElamare DeBOUTTEVILle, Cl., 1973. Conclusions Générales. Ann, Spéléol. 28: 343-345.

DUNCAN,T., 1980. Cladistics for the practicing taxonomist- An eclectic view. Syst. Bot. 5: 149-172. 5: 149-172.

ESTABROOK, G.F.,1978. Some concepts for the stimation of evolutionary relationships in systematic botany. Syst. Bot. 3: 146-150.

GOULD, S.J. \& R.C. LEWONTIN, 1979. The Spandrels of San Marcos and the Panglossian paradigm: a critique of the adaptationist programme. Proc. Roy. Soc. London, s 205: 581-598.

HUEY, R.B., 1987. Phylogeny, history and the comparative method. In: M.E. Feder, A.F. Bennett, W. Burggren \& R.B.Huey (eds). New Directions in Ecological Physiology, 76-98. University Press, Cambridge.

HUSMANN, S., 1966. Versuch einer okologischen Gliederung des interstitiellen Grundwassers in Lebensbereiche eigener Pragung. Arch. Hydl-ohiol. 62: (2): 231-268.

HUSMANN, S., 1971. Ecological studies on Freshwater Meiobenthon in Layers of Sand and Gravel. Smithson. Contr. Zool. 76: 161-169.

LANG, K., 1948. Monographie der Harpacticides. 2 vol. Lund, 1682 pags.

MEACHAN, C.A., 1980. Phylogeny of the Berberidaceae with an evaluation of classifications. Syst. Bot. 5: 149-172.

MEACHAN, C.A. \& T. DUNCAN, 1987. The necessity of Convex Groups in Biological Classifications. Syst. Bot. 12 (1): 78-90.

MESTROV, M.,1962. Un nouveau milieu aquatique souterrain: le biotope hypotelminorheique. C.R. Acad. SC. Paris, 254 (D) 14: 2677-2679.
MOTAS, C., 1962. Procédé des sondages phréatiques. Division du domaine souterrain. - Classification écologique des animaux souterrains- Le psammon. Acta Mus. Maced. sci. Nat. 8: 135-173.

NAUMANN, E., 1932. Grundzüge der regionalen limnologie. Die Binnengewässer, 11, 176 pp.

ORGHIDAM, T., 1953. Un nou domein de viata subterrana Biotopul hiporeic. Bull. sti. sect. Biologie si sfi-Agronon, si sect. geologia si geogr. R.P.R. 7: 3.

PAGEL, M.D. \& P.H. HARVEY, 1988. Recent developments in the analysis of comparative data. Quart.Rev.Biol. 63 (4): 413-440.

PAGEL, M.D. \& P.H. HARVEY, 1989. Comparative methods for examining adaptation depend on evolutionary models. Folia Primatologica 53: 203-220.

PAGEL, M.D. \& P.H. HARVEY, 1990. Taxonomic differences in the scaling of brain on body size among mammals. Science 244: 1589-1593.

RIDLEY. M., 1983. The explanation of organic diversity: the comparative method und adaptations for mating. Oxford University Press, Oxford.

ROUCH, R., 1968. Contribution à la connaissance des harpacticides hypogés (Crustacés, Copepods). Ann. Spéléol. 23: 5-167.

SZALAY, L., 1945. Eine neue Art der Gattung Frontipodopsis Walt. (Hydrachnellae, Acari) aus unterrirdischen Gewassern der Karpatenbeckens. Fragm. faun. hung. 8: 1-5.

TELENIUS, A, A. ANGERBJORN \& O. ERIKSSON, 1989. On phylogenetic ecology. Evolutionary Theory 8: 351-356.

VANDEL, A., 1964. Biospeologie: la biologie des animaur cavernicoles. Gauthier-Villars Editeur, Paris. 619 pags.

VANNOTE, R.C., G.W. MINSHALL, K.W. CUMMINS, J.R. SEDELL \& C.E. CUSHING, 1980. The river continuum concept. Canadian Journal of Fisherirs and Aquatic Sciences. 37: 130-137. 